\title{
The Extreme Precipitation Forecast Table: Improving Situational Awareness When Heavy Rain is a Threat
}

\author{
DIANA R. STOVERN \\ Cooperative Institute of Research for Environmental Sciences, Boulder, Colorado \\ NWS Weather Prediction Center, College Park, Maryland \\ JAMES A. NELSON \\ NWS Weather Prediction Center, College Park, Maryland \\ STAN CZYZYK \\ National Weather Service, Las Vegas, Nevada \\ MARK KLEIN \\ NWS Weather Prediction Center, College Park, Maryland \\ KATIE LANDRY-GUYTON \\ National Weather Service, Houston, Texas \\ KRISTIAN MATTAROCHIA \\ National Weather Service, San Joaquin Valley/Hanford, California \\ EMILIE NIPPER \\ NWS Lower Mississippi River Forecast Center, Slidell, Louisiana \\ JON W. ZEITLER \\ National Weather Service, Austin-San Antonio, Texas
}

(Manuscript received 15 July 2019; review completed 29 June 2020)

\begin{abstract}
A collaborative team of Science and Operations Officers from the National Weather Service (NWS) Weather Forecast Offices (WFOs), hydrologists from the Lower Mississippi River Forecast Center (LMRFC), and management from the Weather Prediction Center (WPC) worked together to develop and transition a tool into NWS operations called the Extreme Precipitation Forecast Table (EPFT). The EPFT was designed to help NWS forecasters improve their situational awareness (SA) when heavy rainfall threatens their county warning area. The EPFT compares Quantitative Precipitation Forecasts (QPF) to Average Recurrence Intervals (ARIs) from the NOAA Atlas-14 to alert forecasters to the potential for climatologically significant and extreme rainfall. A counterpart to the EPFT, called the Extreme Precipitation Assessment Table (EPAT), compares observed precipitation (i.e., Quantitative Precipitation Estimates [QPE]) to inform forecasters as to the climatological significance of impactful rain events. This paper presents cases demonstrating the usefulness of the EPFT and EPAT in helping forecasters improve their SA in real-time operational settings when heavy rain was a threat.
\end{abstract}

\section{Introduction}

When extreme rainfall is a threat, National Weather Service (NWS) forecasters are faced with both scientific and societal challenges when creating a forecast for public dissemination. Many of the scientific challenges arise prior to the event when the forecaster is sifting through large quantities of atmospheric data

Corresponding author address: Diana Stovern, 325 Broadway, Boulder, Colorado, 80305

E-mail: diana.stovern@noaa.gov 
to make an accurate assessment of where, when, and how much precipitation is expected to fall. At any given moment, they have multiple numerical weather prediction models (NWP; see Appendix A for a list of key acronyms used in this paper) providing quantitative precipitation forecasts (QPF) down to hourly resolution in the short-term forecast (i.e., $\leq 1$ day), 3-hourly in the extended short-term forecast (1-2 days) and 6-hourly in the long-term forecast, (3-7 days), which in some models can be available in the extended longterm forecast (8-10 days). Each NWP model contains additional information on the atmospheric ingredients that are known to initiate or enhance extreme rainfall including: the presence of a mid-tropospheric potential vorticity anomaly or meso- $\alpha$ trough, weak-to-moderate vertical wind shear, strong warm-air advection, high precipitable water, high surface dew points, high values of low- to mid-level equivalent potential temperature, moderate convective available potential energy, and low convective inhibition (Maddox et al. 1979; Doswell et al. 1996; Davis 2001; Trier et al. 2006; Jessup and DeGaetano 2008; Schumacher and Johnson, 2008, 2009; Graham and Grumm 2010; Schumacher et al. 2011; Stevenson and Schumacher 2014). Assessing a large volume of data while often under strict time constraints is a challenge that can easily be exacerbated when NWP models are in substantial disagreement with one another. This is usually the case when the forecasted rainfall is on the extreme end of the spectrum and when models with significant differences in resolution are being compared (Herman and Schumacher 2016). In addition, the full potential for flooding cannot be assessed without further considering the characteristics of the watershed and antecedent conditions, such as soil moisture and vegetation coverage (e.g., Jessup and DeGaetano 2008).

Despite the abundance of data available, several NWS service assessments from impactful hydrometeorological events have highlighted that there are a lack of datasets to help forecasters recognize the potential for extreme events. Furthermore, there are even fewer products that help forecasters place the magnitude of the situation into a meaningful context for decision makers. For example, the Southeast United States Floods 2009 service assessment found that forecasters, emergency managers (EMs), and residents did not recognize the magnitude or severity of the forecast until the flood event was well underway (NWS 2010). Another finding that came from this service assessment is that despite the use of Flash Flood Guidance
(FFG), the Flash Flood Monitoring Prediction System (FFMP), and radar precipitation estimates, forecasters had limited historical context or tools to utilize that would help put this information into a climatological perspective. Prior to the South Carolina 2015 floods, when the forecast called for $20+$ in of rain, residents could not comprehend what this meant specifically to them because they lacked a point of reference to compare with this event or a way to visualize it (NWS 2016). In this case, there were no analogs or tools to place the forecast within a historical context that the public could understand. These examples illustrate where the scientific challenges (e.g., model uncertainty or model performance during extreme events) start to blend in with the societal challenges (e.g., decision support messaging or difficulty of communicating extreme events) when extreme hydrometeorological events occur. Once the forecaster has determined where, when, and how much rain is expected, they then have to figure out how to effectively convey the magnitude of the event as well as the potential impacts to their core partners.

Within the last few years, addressing the societal challenges has become the forefront of the forecaster's job duties in the NWS as the agency has started to focus on Impact-Based Decision Support Services (IDSS). The concept of IDSS allows the forecaster to give advice and interpretative services to help core partners, such as emergency personnel and public safety officials, make decisions when weather, water, and climate impacts the lives and livelihoods of the American people (NOAA 2018). Among the most common hazards from extreme rainfall is flooding. Long-term flooding from multi-day storms can lead to massive infrastructure damage and billions of dollars in costs (NCEI 2019). Flash-flooding from a rapid onset of extreme rainfall can result in fatalities due to the more unpredictable nature in both the meteorological processes and hydrologic response (Ashley and Ashley 2008; Gourley and Clark 2018). FFG, which is commonly used in NWS operations, takes into account soil characteristics but has deficiencies that have been well documented. FFG is only valid for $24 \mathrm{hrs}$ or less (Reed et al. 2007; Clark et al. 2014; Gourley and Clark 2018) and has significant spatial discontinuities that exist on River Forecast Center (RFC) boundaries resulting from different methods used in the NWS to derive gridded FFG values (Ortega et al. 2009). Some RFC boundaries divide county warning areas so that a Weather Forecast Office (WFO) could be covered by very different FFG values and very different methods 
of FFG generation (Gourley and Clark 2018). FFG also does not necessarily help convey the full magnitude of a hydrometeorological event (NWS 2016), because it only represents the amount of rainfall needed to reach bankfull conditions. If forecasters are to improve their situational awareness (SA) for effective decision support when extreme rainfall is a threat, they need to have tools that can leverage large amounts of data, facilitate the identification of extreme rainfall in the forecast, and help them convey the information within a meaningful context that their core partners can understand. This is necessary so that in spite of uncertainty in the models and underlying ground conditions, they can still properly inform decision makers on the risks and impacts.

The Extreme Precipitation Forecast Improvement Project was established in 2015 to help provide a solution to remediate some of the issues highlighted in the NWS service assessments mentioned above. The project was pursued by a regionally diverse team of science and operations officers from local WFOs, forecast managers from the Weather Prediction Center (WPC), and hydrologists from the Lower-Mississippi River Forecast Center (LMRFC). The main objective of the project was to integrate new datasets and tools into NWS operations that can help forecasters identify climatologically significant and/or extreme rainfall in the forecast for improved SA and IDSS.

This paper will describe the efforts made by the team to fulfill the objective outlined above, which largely consisted of providing tools called the Extreme Precipitation Forecast Table (EPFT) and Extreme Precipitation Assessment Table (EPAT) to forecasters and hydrologists in the NWS. The EPFT and EPAT are situational awareness tables designed to help forecasters identify climatologically significant and extreme rainfall using Average Recurrence Interval (ARI) data from the NOAA Atlas-14. Section 2 describes the NOAA Atlas-14 dataset and methods used to design and implement the EPFT and EPAT in NWS operations. Cases where these tools provided enhanced SA in realtime forecast settings are presented in section 3. The paper concludes with a discussion in section 4 .

\section{Data and method}

It has been shown that SA tables that highlight important threshold exceedances can facilitate the identification of significant features and hazards in the forecast (Graham et al. 2013). SA tables organize weather data into 2-D matrices, usually with forecast time in one direction and either forecast model or parameter in the other. Values are generally colorcoded to alert forecasters when significant thresholds are reached. The Ensemble Situational Awareness Table (ESAT), originally developed at WFO Salt Lake City and now hosted by WPC (satable.ncep.noaa.gov), is an SA table that has been proven effective at highlighting extreme events in the forecast (Graham et al. 2013). Following the success of the ESAT, the EPFT was designed to facilitate detection of extreme precipitation events by comparing QPF from NWP models and other sources of guidance to ARIs from the NOAA Atlas-14. The EPAT is designed similarly to the EPFT but instead compares quantitative precipitation estimates (QPE) to ARIs to indicate when a climatologically significant rainfall event has been observed.

An ARI represents the average amount of years between precipitation threshold exceedances over a specific duration, or accumulation period, at a given location. The NOAA Atlas-14 contains precipitation frequency estimates (PFEs) based on a $90 \%$ confidence interval for ARIs from 1 to $1000 \mathrm{yrs}$ and durations of five minutes up to 60 days (Bonnin et al. 2004). Gridded PFEs spanning the entire Continental United States (CONUS) for ARIs of 1-, 2-, 5-, 10-, 25-, 50-, and 100-yrs for rainfall durations of six and $24 \mathrm{hrs}$ are incorporated into the EPFT and EPAT. The grids are filled with NOAA Atlas-14 where complete, which include all United States regions except for Texas and the Pacific Northwest (i.e., Washington, Oregon, Idaho, Montana, and Wyoming). Texas and the Pacific Northwest are supplemented with estimates from NOAA Technical Paper 40 (Hershfield 1961) and NOAA Atlas-2 (Miller et al. 1973). Details on how the nationally mosaiced ARI grids were constructed are contained in Herman and Schumacher (2016). It is important to note, however, that the ARI datasets incorporated into each national mosaic are developed with many decades of gauge data based on the availability and density of historical data in each region and may be subject to under-sampling from the use of gauge data alone. This is more likely to occur in rural areas, areas of complex terrain, and within the older ARI datasets. For example, Herman and Schumacher (2018) pointed out that ARI thresholds in Wyoming are likely too low from the NOAA Atlas-2 when compared with the updated NOAAAtlas-14 values in bordering states. They speculated that some areas of Wyoming are likely inaccurate and highly uncertain due to this region being historically rural, especially at the time the threshold estimates were derived. The ARI 
thresholds in Texas obtained from Technical Paper 40 are also considerably more uncertain than the recently updated NOAA Atlas-14 grids released in 2018. Although the updated ARI thresholds contain data from recent landfalling tropical cyclones, there are several precipitation bullseyes along the Texas Gulf coast that are not apparent in the Technical Paper 40 datasets. Thresholds from the NOAA Atlas-14 for ARIs greater than 100 yrs are also highly uncertain because there are little reliable gauge data going back more than 100 yrs. In the EPFT and EPAT, rainfall comparisons are limited to the 100-yr ARI due to the uncertainty in higher ARI thresholds.

For more than half a century, ARIs for specific durations of rainfall have been used in the hydrologic design of flood-prevention systems in the United States (Hershfield 1961; Lopez-Cantu and Samaras 2018). The ARI thresholds significant in this respect are associated with PFEs that when integrated within hydrologic models that consider the characteristics of a watershed, would lead to hydrographs and peak discharges that would result in runoff and inundation of water-control structures (Merkel et al. 2015). ARI thresholds used to define hydrologic design standards can vary across cities and municipalities and depend on the type of structure, drainage area, and risk of failure. In general, larger structures that pose a loss of life, like dams and levees in urban areas, are designed to withstand peak flows associated with at least the 100-yr ARI for a 24-hr duration event (Mays 2011; USDA 2020). The merit in using ARIs for IDSS is that forecasters can get a sense of potential impacts if they have knowledge of the ARI thresholds used in the design of hydrologic structures in their county warning area (CWA). Although research is limited, some studies have linked certain ARI threshold exceedances to reports of flash flooding and resulting impacts (e.g., Lincoln and Thomason 2018; Herman and Schumacher 2018).

The default configuration of the EPFT and EPAT compares the precipitation to the 100-yr ARI, which is an operationally acceptable threshold to define an extreme precipitation event. The values within the EPFT represent the maximum ratio of QPF to the 100yr ARI threshold (QPF/ARI ${ }_{100}$ ) for a user-specified duration and area of interest. The ratio is converted to a percentage and color-coded in the table based on the level of QPF/ARI exceedance (or non-exceedance). The EPFT in Fig. 1a shows QPF/ARI ${ }_{100}$ for a 24-hr duration rainfall capturing the QPF forecast from Hurricane Harvey, initialized at 2200 UTC 26 August 2017. When
QPF from models with temporal resolutions less than six hrs are compared, the EPFT will sum the values to create 6- and 24-hr accumulations for a proper QPF/ARI comparison. If $24 \mathrm{hrs}$ of QPF data are not available, the table will not display results. The user can select a cell within the table, which then displays the grid of QPF/ $\mathrm{ARI}_{100}$ percentages (or QPE/ARI ${ }_{100}$ within the EPAT) to allow for further investigation into the location(s) at risk. They can view QPF guidance contoured in the context of ARIs from 1 to $100 \mathrm{yrs}$, as well as the QPF and ARI grids used to calculate the ratios from the EPFT's user interface.

A key for interpreting the EPFT with the default configuration (i.e., 100-yr ARI) was provided to NWS forecasters to facilitate analysis of the results (Fig. 1b). The key was designed based on several post-storm event analyses conducted out of the State College, Pennsylvania WFO (Grumm 2016a, 2016b). A case study of the southern United States heavy rain and floods of March 2016 found that the GFS (see Appendix B for a list of model abbreviations) produced QPF/ARI ${ }_{100}$ ratios between $75 \%$ and $100 \%$ of the $100-\mathrm{yr}$ ARI for 24-hr duration rainfall, with nearly all 24-hr forecasts, initialized starting at 0000 UTC 7 March and valid for the period ending 1800 UTC 9 March, capturing at least $50 \%$ of the $100-\mathrm{yr}$ ARI. According to QPE from the NCEP Stage IV Precipitation Analysis product (Stage IV; Lin and Mitchell 2005), QPE/ARI ${ }_{100}$ ratios were between 125 and $150 \%$ for the 24-hr observed rainfall ending 1800 UTC 9 March. An analysis of the historic West Virginia floods of June 2016 (Grumm 2016b) showed similar results, with the wettest runs of the GFS barely exceeding $75 \%$ of the 100 -yr ARI for 24 hr duration rainfall, whereas QPE comparisons verified with ratios closer to $125 \%$. A main finding uncovered from both studies is that the GFS, like many other models that use cumulus parameterization schemes rather than explicitly solving for convection, has difficulty producing extreme QPF amounts in localized, strongly forced events. Herman and Schumacher (2016) similarly found that the GEFS mean QPF rarely predicts 100-yr events, whereas QPF from the HRRR and WRF-NSSL verify much better with observed 100yr exceedances of 6-hr duration rainfall. It follows that the forecaster should have heightened awareness to the potential for an extreme event, and thus damaging impacts to life and property, when QPF/ARI ${ }_{100}$ values within the table start to near or exceed $75 \%$. The key does not account for the areal extent of the precipitation system or the antecedent conditions, which are both 


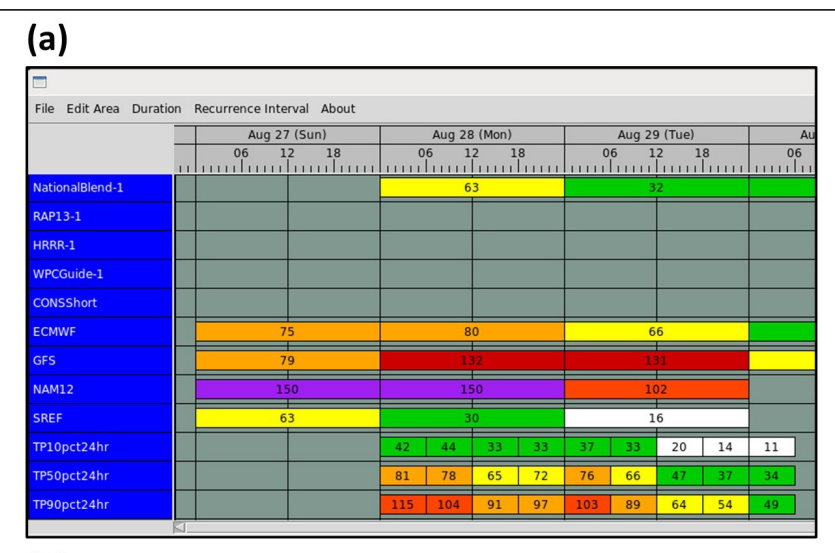

(b)

\begin{tabular}{|c|c|}
\hline QPF/ARI* & Potential for Damaging Impacts to Life and Property** \\
\hline$<25 \%$ & Minimal \\
\hline $25-50 \%$ & Low \\
\hline $50-75 \%$ & Moderate \\
\hline $75-100 \%$ & High \\
\hline $100-125 \%$ & Very High \\
\hline $125-150 \%$ & Emergency \\
\hline $150-175 \%$ & Catastrophic \\
\hline $\begin{array}{l}\text { *Compared to the 100-year ARI rainfall estimates for durations of 6- and 24-hours } \\
\text { **Impacts from flooding also depend on soil moisture and type, terrain, areal coverage of rainfall, and } \\
\text { geography (urban vs. rural). }\end{array}$ \\
\hline
\end{tabular}

Figure 1. a) EPFT Initialized at 2200 UTC 26 August 2017 showing the max QPF/ARI 100 ratio associated with the QPF forecasts from Hurricane Harvey (i.e., TX/LA domain). See Appendix B for a list of model abbreviations and descriptions. b) The following key was provided to NWS forecasters to help identify significant values in the table. Click image for an external version; this applies to all figures and hereafter.

important aspects that need to be considered when determining potential impacts from extreme rainfall. In addition, the key is only applicable to QPF comparisons with the 100-yr ARI. Although there is the ability in the EPFT to compare QPF with lower ARI thresholds, additional studies would need to be completed to refine the key and facilitate analysis of the results.

The EPFT and EPAT are available to NWS forecasters at all CONUS-wide WFOs, RFCs, and the Weather Prediction Center via the Advanced Weather Interactive Processing System (AWIPS). The value in using AWIPS to host the EPFT is that it allows NWS forecasters and hydrologists to take advantage of the maximum amount of QPF guidance available for a streamlined assessment of when and where extreme precipitation could be a threat. AWIPS has the unique ability for tools to be created that can leverage large amounts of model data as well as guidance from nearby WFOs, RFCs, and WPC for enhanced collaboration and coordination during the forecast generation process.
In the next section, we will demonstrate cases where the EPFT and EPAT enhanced situational awareness in real-time operational settings.

\section{Operational use-cases}

\section{a. Anticipating an atmospheric river event}

An atmospheric river impacted southern California during 21-23 March 2018. The NWS San Joaquin Valley/Hanford Office (HNX) was at risk for heavy rainfall from this event, and with the prevalence of burn scars in their CWA, was concerned about the possibility of mudslides and flood impacts. A forecaster at HNX initialized the EPFT on 1900 UTC 20 March 2018, comparing 6-hr QPF from 20 different sources of guidance to the 100-yr ARI (Fig. 2a). Using the metric that $\mathrm{QPF} / \mathrm{ARI}_{100}$ ratios exceeding $75 \%$ are indicative that an extreme rainfall event is possible, the EPFT allowed the forecaster to key in on the timeframe 0000-0600 UTC 22 March 2018, corresponding to Wednesday afternoon/evening. Several models forecasted 6-hr rainfall exceeding $75 \%$ of the 100 -yr ARI, including the HIRESWarw, HIRESWnmm, NAM12, and GFS1 hr. The 24-hr comparison showed five QPF sources, including WPCGuide, exceeding $75 \%$ of the 100 -yr ARI (Fig. 2b). A plot of the ratios generated from the HIRESWnmm valid at 0000 UTC 22 March shows an example of where some of the higher values were located (Fig. 3a). The HNX forecaster indicated that flood impacts (e.g., road wash-outs, mudslides) could have been possible if the storm cell in the HIRESWnmm moved over one of the many burn scars in the CWA. The burn scar from the 2017 Detwiler fire was of particular concern, and the grid generated from the CMCnh during 0000 UTC

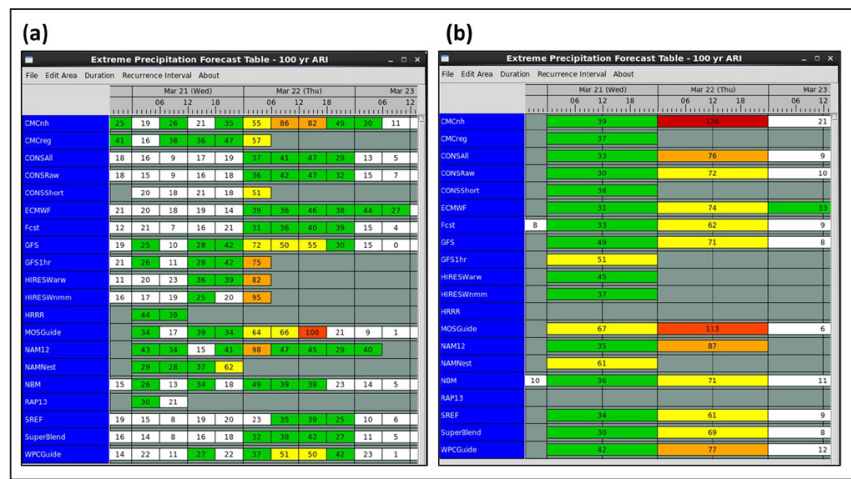

Figure 2. EPFT initialized at 1900 UTC 20 March 2018 showing QPF/ARI ${ }_{100}$ over the HNX CWA for a) 6-hr and b) 24-hr duration rainfall. 


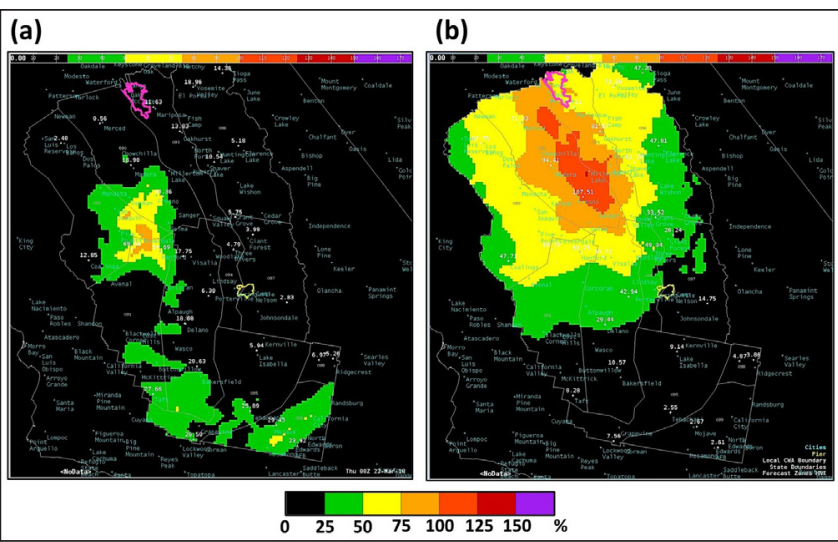

Figure 3. Select images generated from the EPFT in Fig. 2 displaying the spatial extent of the QPF/ARI ${ }_{100}$ values from the a) 6-hr HIRESWRFnmm valid starting at 0000 UTC 22 March $2018(\max =95 \%)$ and b) 24hr CMCnh valid starting 0000 UTC 22 March 2018 $(\max =126 \%)$. The magenta outline depicts the bounds of the Detwiler burn scar.

22 March to 0000 UTC 23 March shows QPF/ARI ${ }_{100}$ values exceeding $75 \%$ in and around the area (Fig. 3b).

This information consolidated in the EPFT helped the forecaster to craft their message when informing core partners of the risk imposed by the atmospheric river event in their CWA. Here is a quote from the forecaster regarding the event:

The EPFT showed the potential for heavy rainfall and sufficient rainfall rates to produce flooding over the Detwiler Burn Scar, associated with a narrow cold frontal rainband that was fed by an atmospheric river on March 22,2018 . The enhanced situational awareness provided by the tool helped the NWS Hanford office communicate potential flood impacts with several hours of lead time for Mariposa County emergency managers. This allowed an elementary school to be evacuated in a timely manner. Potential flood impacts were also conveyed to the NWS Western Region Regional Operations Center and the California Governor's Office of Emergency Services, which ultimately aided decision making on a state-wide scale.

Through personal communication, the forecaster indicated that it was a wet year, so that antecedent conditions lowered the ARI thresholds they considered important while assessing the EPFT values.
SA was additionally enhanced due to the forecaster's previous use of the EPFT to self-calibrate their own awareness toward the values in the EPFT that are significant for impacts. During the 2017 wet season, the forecaster ran the EPFT at 2200 UTC 6 February 2017, comparing QPF to the 50-yr ARI (QPF/ARI $\left.{ }_{50}\right)$ for a 6-hr duration rainfall (Fig. 4a). Several pieces of guidance (i.e., GFS, HIRESWarw, HIRESWnmm, MOSGuide) had indicated that there was potential for a 50-yr ARI event to occur somewhere within the HNX CWA between 1200 UTC 7 February and 0000 UTC 8 February 2017. The event verified with 6-hr rainfall closer to a 25-yr ARI according to Stage IV QPE (Fig. $4 \mathrm{~b}$ ), which had led to local storm reports of flooded roadways and roads blocked from rockslides and landslides during the same period.

Regarding the 21-23 March 2018 atmospheric river event, knowledge of other risk factors like high

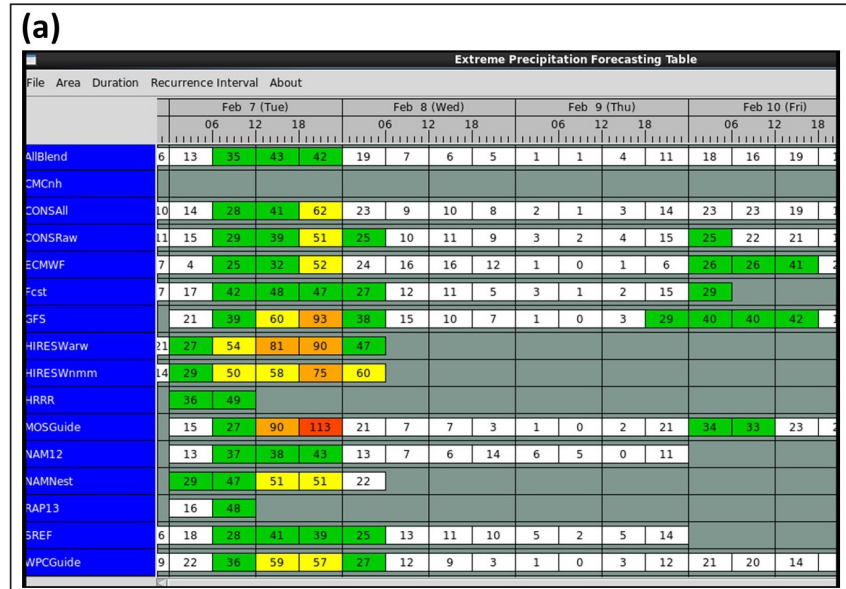

\section{(b) 1200 UTC 7 Feb 2017}

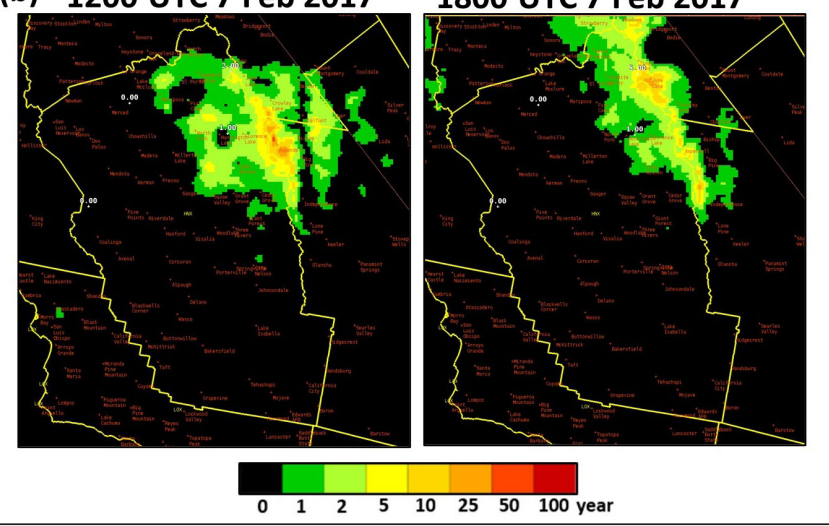

Figure 4. a) The EPFT initialized at 2200 UTC 6 February 2017 showing the $\max$ QPF/ARI ${ }_{50}$ over the HNX CWA. b) Observed 6-hr ARI threshold exceedances according to Stage IV QPE valid starting at 1200 UTC and 1800 UTC 7 February 2017. 
soil moisture and burn scars and previous experience correlating specific ARI thresholds with impacts in the HNX CWA were all necessary so that the forecaster could deliver effective decision support in a timely manner.

\section{b. Enhanced situational awareness at LMRFC}

On 22 October 2017, a slow-moving mesoscale convective system (MCS) fed by anomalously moist, low-level confluent flow had impacted south-central Louisiana and southern Mississippi with heavy rain and flash flooding. An LMRFC hydrologist ran the EPAT and EPFT during the event to assess how each tool could be used to enhance situational awareness for this particular event. Prior to running the EPAT, the hydrologist was aware that 8-11 in of rain fell overnight (in about six hrs), which caused a major highway to flood. A social media post from the Louisiana State Police was provided showing a picture of a flooded road and detour information (Fig. 5a). Consequently, by running the EPAT the hydrologist was able to identify the ARI-equivalent rainfall amounts that corresponded to the impacts shown in Fig. 5a. During the 0000-0600 UTC and 0600-1200 UTC periods on 22 October, several QPE observing sources within the EPAT (Fig. $5 b$ ) indicated that rainfall had exceeded the 10-yr ARI from the MCS that had anchored itself over southcentral Louisiana (Fig. 5c).

In regard to the values in the EPAT, the hydrologist stated:

Given the impacts from the previous 12 hours, the EPAT had provided guidance for what impacts could be expected if convection associated with this system continued to produce 10-yr ARI threshold exceedances, let alone 100-yr ARI exceedances.

The hydrologist initialized the EPFT at 1700 UTC 22 October, which had shown the HRRR and HIRESWnmm forecasting rainfall exceeding the 100-yr ARI over the next 6-hr period (Fig. 6a). The hydrologist noted that both models depicted a band of 100-yr ARI rainfall moving into southern Mississippi (e.g., Fig. 6b), which include drainages that feed the Biloxi and Wolf Rivers. Given the additional situational awareness provided by the EPFT and EPAT, the hydrologist was confident in their decision to put out forecast hydrographs for gauges on the Biloxi and Wolf

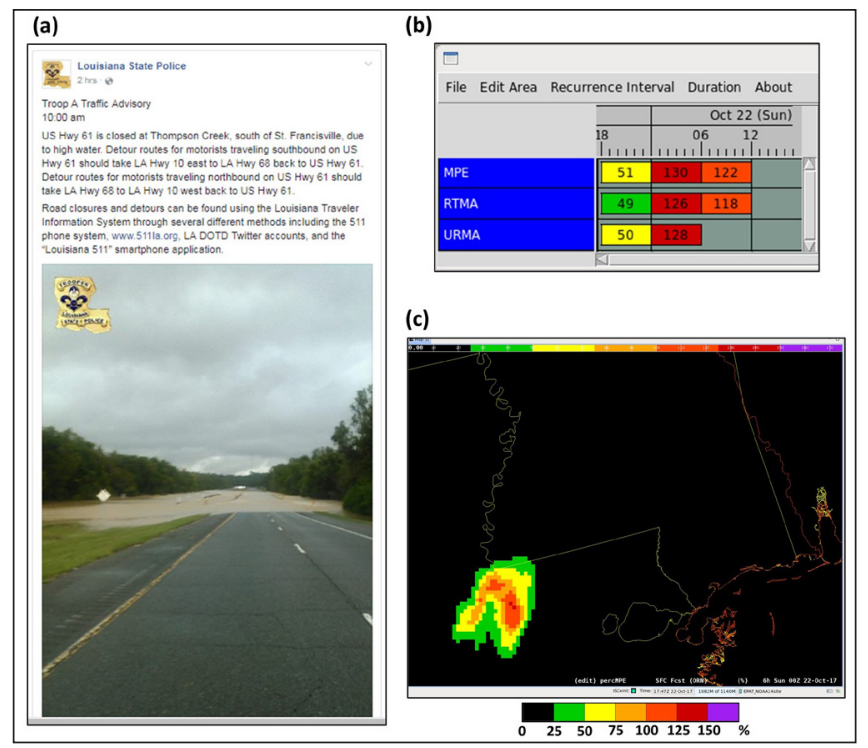

Figure 5. From an MCS-driven heavy-rain event that occurred 22 October 2017: a) LA state police reported road closures from a flash flood on social media. b) The EPAT corresponding to the event had shown 6-hr QPE exceeding the 10-yr ARI threshold according to 3 QPE observing sources starting at 00 UTC and 2 QPE sources starting at 06 UTC. Shown in c) are the 6-hr QPE/ARI ${ }_{10}$ gridded ratios from the MPE valid starting at 00 UTC 22 October.

Rivers that are shown reaching Flood stage (Fig. 7a) and Action stage (Fig. 7b), respectively.

The hydrologist further commented that except in areas of steep terrain, the 10-yr ARI threshold is often defaulted to when using the EPFT. With the exception of land-falling tropical cyclones, higher ARI threshold exceedances are rarely observed within their forecast area. From using EPAT, they found that the 10-yr ARI has the most benefit in capturing flood impacts, especially in areas less than $200 \mathrm{mi}$ from the Gulf of Mexico coast. In this area, the terrain is flatter, leading to poor drainage and ponding of water. In areas of steeper terrain, they look for 25-yr ARI exceedances within the EPFT. Because of the terrain changes within their forecast area of responsibility, the rainfall durations used are dependent on the response of local creeks, streams and tributaries. In steeper terrain, ARIs associated with shorter durations of rainfall (i.e., $<6$ hrs) are a better indicator of flooding, whereas ARIs associated with longer durations (i.e., $\geq 6 \mathrm{hrs}$ ) are more widely used along the coast and locations just inland. 


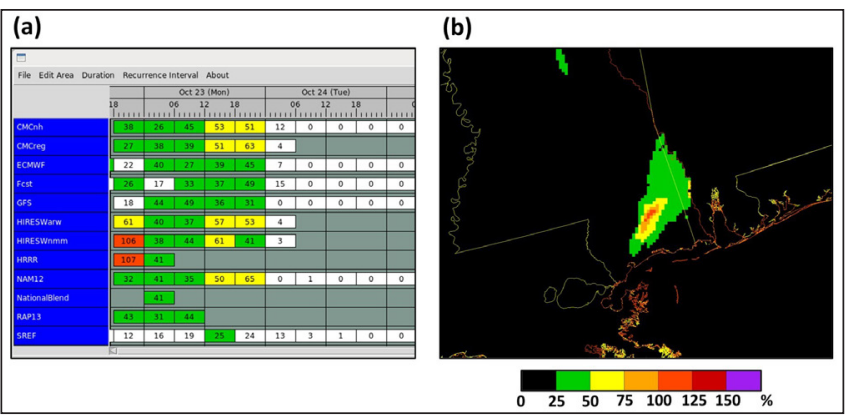

Figure 6. a) The EPFT initialized around 1700 UTC 22 October 2018. b) An EPFT-generated grid showing the spatial extent of the 6-hr QPF/ARI 100 values from the HRRR ( $\max =107 \%)$ valid starting at 1800 UTC 22 October 2018.

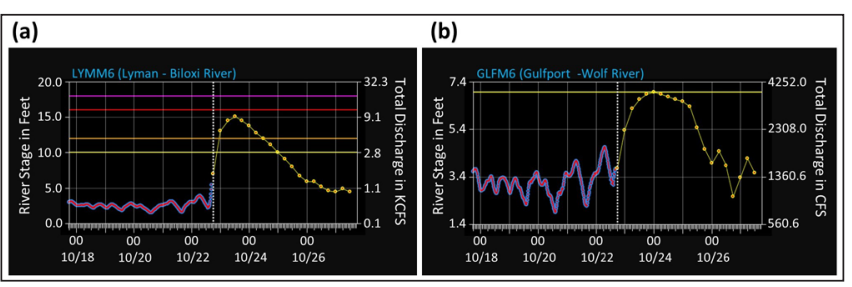

Figure 7. The updated river stage forecast (yellowdotted line) for the a) Biloxi River (flood stage $=12 \mathrm{ft}$ ) and $\mathrm{b}$ ) Wolf River (flood stage $=8 \mathrm{ft}$ ). The horizontal lines represent flood categories: Action Stage (Yellow), Flood Stage (Orange), Moderate Flood Stage (Red) and Major Flood Stage (Purple).

\section{Summary and discussion}

The Extreme Precipitation Forecast Improvement Project developed and transitioned situational awareness tools into NWS operations for the purpose of improving situational awareness and IDSS for impactful hydrometeorological events. The EPFT allows forecasters to compare multiple sources of QPF guidance to ARI threshold exceedances to alert them to when the models are predicting an extreme or climatologically significant precipitation event, whereas the EPAT helps them to identify when a climatologically significant precipitation event has been observed. Continual use of the EPAT will allow offices to calibrate their ARIs to impacts and enhance the use of the EPFT as an effective SA Tool.

Two use-cases are presented where the EPFT and EPAT helped improve situational awareness and had implications to IDSS during heavy rain events associated with an atmospheric river in California and an MCS in the southeastern United States. There were key similarities between how the tools were used in each event that made it effective: 1) Previous use of the EPFT and/or EPAT was necessary to get a sense of the impacts that can result when different ARI thresholds are exceeded; 2) Recognition of multiple sources of guidance nearing or exceeding the ARI threshold of interest helped increase confidence in the message; 3) Use of the EPFT in conjunction with products that depict antecedent conditions helped to provide a full assessment of flood potential.

We should note here that there are some regions in the United States where the EPFT and EPAT may be more unreliable due to the combined poor performance of the inputs, particularly in the intermountain West. Here, there are significant gaps in both gauge data and radar coverage so that both the ARI and QPE inputs could be unreliable and have high uncertainty (Cocks et al. 2016; Herman and Schumacher, 2018). Confidence limits associated with the ARI thresholds are provided through NOAA's Hydrometeorological Design Studies Center, but they have not been incorporated into either tool. Forecasters should also be aware that the performance of the EPFT depends on the model QPF going into it, to which no additional bias-correction is applied before the values in the table are calculated. Thus, depending on the type of weather system being forecasted, high-resolution models can have a highQPF bias and display high ARI exceedances, while low-resolution models can have a low-QPF bias and thus low-ARI exceedances.

Feedback from NWS forecasters reveal that they still view ARIs as a relatively new and advanced statistical concept. If they have not had enough experience or training with ARIs themselves, they have trouble relating them to on-the-ground impacts. If these challenges are to be remedied, more locally conducted research is necessary into the impacts that can be expected when certain ARI thresholds are forecasted.

The EPFT could benefit from the inclusion of more probabilistic information to help forecasters identify the likelihood of a certain ARI event occurring. Probabilistic QPF (PQPF) from WPC has been incorporated into the EPFT, but additional PQPF from the National Blend of Models, which has been released in version 3.2, will also add substantial value. There are plans to work NBM's calibrated probabilistic QPF into the EPFT so that the information can be recast in the context of ARIs by percentile, which will help forecasters identify the probability of a specific ARI threshold being exceeded. The value here, as noted in Craven et al. 2020, is that forecasters can use this information to convey the most 
likely scenario and potential alternative outcomes when extreme rainfall is a threat. The use of these datasets will allow forecasters a larger toolset to build effective IDSS messaging for extreme rainfall events.

Acknowledgments: This project was funded by the NWS Office of Science and Technology Integration under the NOAA Cooperative Agreement award number NA17OAR4320101. The authors would like to thank Dr. David Novak for founding the Extreme Precipitation Forecast Improvement Project. Expertise that helped guide this project was also provided by Dr. Russ Schumacher, Dr. Trevor Alcott, and Rich Grumm. The national ARI mosaiced grids were provided by Dr. Greg Herman out of the Precipitation Systems Research Group from Colorado State University. The authors would also like to thank Tom LeFebvre in ESRL's Global Services Division for providing technical assistance in the development of the EPFT. Finally, we would like to thank the three reviewers for their thoughtful comments that helped improve the manuscript.

\section{APPENDIX A}

\section{Key Acronyms}

AARI - Average Recurrence Interval

AWIPS - Advanced Weather Interactive Processing System

CONUS - Continental United States

CWA - County Warning Area

EM - Emergency Manager

EPAT - Extreme Precipitation Assessment Table

EPFT - Extreme Precipitation Forecasting Table

ESAT - Ensemble Situational Awareness Table

FFG - Flash Flood Guidance

FFMP - Flash-Flood Monitoring and Prediction system

HNX - San Joaquin San Joaquin Valley/Hanford Office

IDSS - Impact-based Decision Support Services

LMRFC - Lower Mississippi River Forecast Center

MCS - Mesoscale Convective System

NCEP - National Centers for Environmental Prediction

NOAA - National Oceanic and Atmospheric Administration

NWP - Numerical Weather Prediction

NWS - National Weather Service

PFE - Precipitation Frequency Estimate

PQPF - Probabilistic QPF

QPE - Quantitative Precipitation Estimate

QPF - Quantitative Precipitation Forecast

RFC - River Forecast Center

SA - Situational Awareness

WFO - Weather Forecast Office

WPC - Weather Prediction Center

WRF-NSSL - Weather Research Forecast National Severe Storms Laboratory 


\section{APPENDIX B}

\section{Model Abbreviations and Descriptions}

AAllBlend - Average of CONSAll and previous forecast

CMC - Canadian Meteorological Center model

CMCreg - CMC regional model

CMCnh - CMC global model

CONSAll - a consensus blend of all MOS type models and all deterministic models.

CONSRaw - a consensus blend of all deterministic models

CONSShort - a consensus blend of short-term, hourly model guidance.

ECMWF - European Center for Medium Range Weather Forecasting model

Fcst - The WFO's QPF

GEFS - Global Ensemble Forecasting System

GEFS/R - Global Ensemble Forecast System Reforecast climatology

GEFSMEAN - Ensemble mean of the GEFS

GFS - Global Forecast System

GFS 1hr - GFS interpolated to a 1-hr temporal resolution

HREF - High-Resolution Ensemble Forecast system

HIRESWarw - NCEP version of the Weather Research and Forecast model - Advanced Research WRF

HIRESWnmm - NCEP version of the Weather Research and Forecast model - Nonhydrostatic Mesoscale Model

HRRR - High-Resolution Rapid Refresh model

MOS - Model Output Statistics

MOSGuide - MOS gridded QPF guidance

MRMS - Multi-Radar/Multi-Sensor System

MPE - Multi-sensor Precipitation Estimate

NAM - North American Model

NAM12 - NAM produced at a12-km grid spacing

NAMNest - NAM 3-km nest

NationalBlend - National Blend of Models

NBM - National Blend of Models

NDFD - National Digital Forecast Database

RAP13 - Rapid Refresh model (13-km grid spacing)

RTMA - Real-Time Mesoscale Analysis QPE

SREF - Short-Range Ensemble Forecast model

TP10pct24hr - 10th percentile QPF from WPC's 46-member ensemble

TP50pct24hr - 50th percentile QPF from WPC's 46-member ensemble

TP90pct24hr - 90th percentile QPF from WPC's 46-member ensemble

URMA - Unrestricted Mesoscale Analysis QPE

WPCGuide - Weather Prediction Center deterministic QPF Guidance 


\section{REFERENCES}

Ashley, S. T. and W. S. Ashley, 2008: Flood fatalities in the United States. J. Appl. Meteor. Climatol., 47, 805818. CrossRef.

Bonnin, G. M., D. Martin, B. Lin, T. Parzybok, M. Yekta, and D. Riley, 2004: Precipitation-Frequency Atlas of the United States. NOAA Atlas 14, Vol. 1, 271 pp. [Available online at www.nws.noaa.gov/oh/hdsc/PF documents/ Atlas14 Volume1.pdf.]

Clark, R. A., J. J. Gourley, Z. L. Flamig, Y. Hong, and E. Clark, 2014: CONUS-wide evaluation of National Weather Service flash flood guidance products. Wea. Forecasting, 29, 377-392. CrossRef.

Cocks, S. B., S. M. Martinaitis, B. Kaney, J. Zhang, and K. Howard, 2016: MRMS QPE performance during the 2013/14 Cool Season. J. Hydrometeor., 17, 791-810. CrossRef.

Craven, J. P., D. E. Rudack, and P. E. Shafer, 2020: National Blend of Models: A statistically post-processed multimodel ensemble. J. Operational Meteor., 8 (1), 1-14. CrossRef.

Davis, R. S., 2001: "Flash Flood Forecast and Detection Methods", in Doswell, C.A. (eds.), Severe Convective Storms, pp. 481-525, Meteor. Monogr., No. 50, Amer. Meteor. Soc., Boston, MA. CrossRef.

Doswell III, C. A., H. E. Brooks, and R. A. Maddox, 1996: Flash flood forecasting: An ingredients-based methodology. Wea. Forecasting, 11, 560-581. CrossRef.

Gourley, J. J., and R. A. Clark III, 2018: "Real-Time Flash Flood Forecasting." Oxford Research Encyclopedia of Natural Hazard Science. Oxford University Press. (Date of access 6 Dec. 2019.) CrossRef.

Graham, R., T. Alcott, N. Hosenfeld, and R. H. Grumm, 2013: Anticipating a rare event utilizing forecast anomalies and a situational awareness display: The western U.S. storms of 18-23 January 2010. Bull. Amer. Meteor. Soc., 94, 1827-1836. CrossRef.

Graham, R. A., and R. H. Grumm, 2010: Utilizing normalized anomalies to assess synoptic-scale weather events in the western United States. Wea. Forecasting, 25, 428445. CrossRef.

Grumm, R. H., 2016a: Southern Heavy Rain and Floods of 8-10 March 2016, National Weather Service State College, PA. [Available online at www.cms.met.psu.edu/ sref/severe/2016/09Mar2016.pdf.]

, 2016b: Historic and Deadly West Virginia Floods of 23-24 June 2016, National Weather Service, State College, PA. [Available online at http://cms.met.psu. edu/sref/severe/2016/09Mar2016.pdf.]

Herman, G. R., and R. S. Schumacher, 2016: Extreme precipitation in models: An evaluation. Wea. Forecasting, 31, 1853-1879. CrossRef.
, and 2018: Flash flood verification: Pondering precipitation proxies. J. Hydrometeor, 19, 1753-1776. CrossRef.

Hershfield, D. M., 1961: Rainfall frequency atlas of the United States: For durations from 30 minutes to 24 hours and return periods from 1 to 100 yrs. U.S. Weather Bureau Tech. Paper 40, 61 pp. [Available online at www. nws.noaa.gov/oh/hdsc/PF_documents/TechnicalPaper No40.pdf.]

Jessup, S. M. and A. T. DeGaetano, 2008: A statistical comparison of the properties of flash flooding and nonflooding precipitation events in portions of New York and Pennsylvania. Wea. Forecasting, 23, 114-130. CrossRef.

Lin, Y., and K. E. Mitchell, 2005: The NCEP Stage II/IV hourly precipitation analyses: Development and applications. 19th Conf. on Hydrology, San Diego, CA, Amer. Meteor. Soc., 1.2, 4 pgs. [Available online at http://citeseerx.ist.psu.edu/viewdoc/ download?doi=10.1.1.182.2080\&rep=rep1\&type $=$ pdf. $]$

Lincoln, W. S., and R. F. L. Thomason, 2018: A preliminary look at using rainfall average recurrence intervals to characterize flash flood events for real-time warning forecasting. J. Operational Meteor., 6 (2), 13-22. CrossRef.

Lopez-Cantu, T. and C. Samaras, 2018: Temporal and spatial evaluation of stormwater engineering standards reveals risks and priorities across the United States. Environ. Res. Lett., 13, 12 pp. CrossRef.

Maddox, R. A., C. F. Chappell, and L. R. Hoxit, 1979: Synoptic and meso- $\alpha$ scale aspects of flash flood events. Bull. Amer. Meteor. Soc., 60, 115-123. CrossRef.

Mays, L. W., 2011: Water Resources Engineering. John Wiley \& Sons, Second Edition, 842 pp.

Merkel, W. H., H. Fox Moody, Q. D. Quan, 2015: Design Rainfall Distributions Based on NOAA Atlas 14 Rainfall Depths and Durations. United States Department of Agriculture, Natural Resources Conservation Service, 9 pp. [Available online at acwi.gov/sos/pubs/3rdJFIC/ Contents/1F-Merkel.pdf.]

Miller, J. F., R. H. Frederick, and R. J. Tracey, 1973: "Precipitation-Frequency Atlas of the Western United States, Vol. 1", Montana 2, NOAA Atlas 2, 33 pp. [Available online at www.nws.noaa.gov/oh/hdsc/PF documents/Atlas2 Volume1.pdf.]

NCEI (NOAA National Centers for Environmental Information), 2019: U.S. Billion-Dollar Weather and Climate Disasters. [Available online at www.ncdc.noaa. gov/billions/.]

NOAA, 2018: National Weather Service (NWS) Service Description Document (SDD), Impact-Based Decision Support Services for NWS Core Partners. 24 pp. [Available online at www.nws.noaa.gov/im/IDSS $\underline{\text { SDD V1 0.pdf }}$ 
NWS, 2010: Southeast United States Floods, September 18-23, 2009. NWS Service Assessment, 71 pp. [Available online at www.weather.gov/media/ publications/assessments/se floods10.pdf.] , 2016: The Historic South Carolina Floods of October 1-5, 2015. NWS Service Assessment, 113 pp. [Available online at www.weather.gov/media/publications/ assessments/SCFlooding_072216_Signed_Final.pdf.]

Ortega, K. L., T. M. Smith, K. L. Manross, K. A. Scharfenberg, A. Witt, A. G. Kolodziej, and J. J. Gourley, 2009: The Severe Hazards Analysis and Verification Experiment. Bull. Amer. Meteor. Soc., 90, 1519-1530. CrossRef.

Reed, S., J. Schaake, and Z. Zhang, 2007: A distributed hydrologic model and threshold frequency-based method for flash flood forecasting at ungauged locations. $J$. Hydrol., 337, 402-420. CrossRef.

Schumacher, R. S., and R. H. Johnson, 2008: Mesoscale processes contributing to extreme rainfall in a midlatitude warm-season flash flood. Mon. Wea. Rev., 136, 39643986. CrossRef. , and _ 2009: Quasi-stationary, extreme-rainproducing convective systems associated with midlevel cyclonic circulations. Wea. Forecasting, 24, 555-574. CrossRef.

, T. J. Galarneau, Jr., and L. F. Bosart, 2011: Distant effects of a recurving tropical cyclone on rainfall in a midlatitude convective system: A high-impact predecessor rain event. Mon. Wea. Rev., 139, 650-667. CrossRef.

Stevenson, S. N., and R. S. Schumacher, 2014: A 10-yr survey of extreme rainfall events in the central and eastern United States using gridded multisensor precipitation analyses. Mon. Wea. Rev., 142, 3147-3162. CrossRef.

Trier, S. B., C. A. Davis, D. A. Ahijevych, M. L. Weisman, and G. H. Bryan, 2006: Mechanisms supporting longlived episodes of propagating nocturnal convection within a 7-day WRF model simulation, J. Atmos. Sci., 63, 2437-2461. CrossRef.

United States Department of Agriculture (USDA), Natural Resources Conservation Service (NRCS), Engineer Hydrology Training Series, Module 109: Design Hydrology. 44 pp., [Available online at www.nrcs.usda. gov/Internet/FSE DOCUMENTS/stelprdb1082998. pdf]. Accessed 9 April 2020. 